\title{
Influence of measurement inaccuracies on determination of left ventricular mass by $M$ mode echocardiography
}

\author{
Claudia Stöllberger, Igor Holländer, Leonid Dimitrov, Jörg Slany
}

\begin{abstract}
Objective-To determine to what extent inaccuracies in measuring the end diastolic diameter of the left ventricle, the interventricular septum, and the posterior wall, by $M$ mode echocardiography influence the left ventricular mass calculated by the Devereux's formula. Design-Mathematical model.

Results-Relatively small measurement inaccuracies such as $5 \%$, which are known to be inherent in the echocardiographic method, will result in "changes" of left ventricular mass in the range of $8 \%$ to $15 \%$. This is equivalent to expected changes in left ventricular mass seen during treatment.

Conclusions-The use of Devereux's formula to calculate left ventricular mass is limited by measurement inaccuracies in individual patients.
\end{abstract}

(Heart 1996;75:312-313)

Keywords: left ventricular mass; measurement inaccuracy; Devereux's formula; $M$ mode echocardiography

Several clinical studies have emphasised the prognostic value of left ventricular mass (LVM). ${ }^{12}$ Therefore assessment of LVM is an important issue in the management of hypertensive patients, particularly for monitoring the effects of antihypertensive drugs. LVM is usually assessed by $M$ mode echocardiography and the application of Devereux's formula ${ }^{3}$ :

Zweite Medizinische Abteilung der Krankenanstalt Rudolfstiftung, Vienna, Austria C Stöllberger J Slany

Österreichische Akademie der Wissenschaften, Vienna, Austria I Holländer L Dimitrov

Correspondence to: Dr Stöllberger, Zweite Medizinische Abteilung der Krankenanstalt Krankenanstalt A-1030 Vienna, Austria. Accepted for publication 26 September 1995
$L V M=1.04 \times\left[(E D D+S E P+P W)^{3}-E^{3}\right]-13.6$.

In this formula, EDD, SEP, and PW are the end diastolic diameter of the left ventricle, interventricular septal thickness, and posterior wall thickness, measured in centimetres. The resulting quantity, LVM, is calculated in grams.

The repeatability and precision of this method in individual patients are questionable because of determination of these variables from the echocardiographic recording is inaccurate. ${ }^{4-6}$ The aim of the present study was to determine by applying a mathematical model how measurement inaccuracies of EDD, SEP, and PW influence LVM.

\section{Methods}

For the mathematical model we assumed the correct ("true") values of the variables EDD, SEP, and PW to be $\mathrm{EDD}_{\mathrm{C}}, \mathrm{SEP}_{\mathrm{C}}$, and $\mathrm{PW}_{\mathrm{C}}$, respectively. The observed (inaccurate) values (EDD, SEP, and PW) are error-prone and are expressed each as a sum of the correct value plus some error quantities $\left(d_{\mathrm{EDD}}, \mathrm{d}_{\mathrm{SEP}}\right.$, and $\left.\mathrm{d}_{\mathrm{PW}}\right)$ :

$$
\begin{aligned}
\mathrm{EDD} & =\mathrm{EDD}_{\mathrm{C}}+\mathrm{d}_{\mathrm{EDD}}, \\
\mathrm{SEP} & =\mathrm{SEP}_{\mathrm{C}}+\mathrm{d}_{\mathrm{SEP}}, \\
\mathrm{PW} & =\mathrm{PW}_{\mathrm{C}}+\mathrm{d}_{\mathrm{PW}} .
\end{aligned}
$$

If the true LVM is calculated using the correct values, the result is:

$\mathrm{LVM}_{\mathrm{C}}=1.04 \times\left[\left(\mathrm{EDD}_{\mathrm{C}}+\mathrm{SEP}_{\mathrm{C}}+\mathrm{PW}_{\mathrm{C}}\right)^{3}-\mathrm{EDD}_{\mathrm{C}}^{3}\right]-13 \cdot 6$

However, by using the observed values EDD, SEP, and PW, we get

$$
\begin{aligned}
\operatorname{LVM}=1.04 \times\left[\left(\left(\mathrm{EDD}_{\mathrm{C}}+\mathrm{d}_{\mathrm{EDD}}\right)+\left(\mathrm{SEP}_{\mathrm{C}}+\mathrm{d}_{\mathrm{SEP}}\right)+\right.\right. \\
\left.\left.\left(\mathrm{PW}_{\mathrm{C}}+\mathrm{d}_{\mathrm{PW}}\right)\right)^{3}-\left(\mathrm{EDD}_{\mathrm{C}}+\mathrm{d}_{\mathrm{EDD}}\right)^{3}\right]-13.6
\end{aligned}
$$

instead of the correct value. To determine how strongly LVM is influenced by the individual errors of the quantities EDD, SEP, and PW entering the formula, we analysed the relation between the independent variables $d_{\mathrm{EDD}}, \mathrm{d}_{\mathrm{SEP}}$, $\mathrm{d}_{\mathrm{PW}}$, and the dependent variable $\mathrm{d}_{\mathrm{LVM}}$ which is the difference between the true and the calculated LVM.

In the first case, we let the variable $d_{\mathrm{EDD}}$ be zero, and evaluated the function

$$
\begin{gathered}
\mathrm{LVM}=1.04 \times\left[\left(\mathrm{EDD}_{\mathrm{C}}+\left(\mathrm{SEP}_{\mathrm{C}}+\mathrm{d}_{\mathrm{SEP}}\right)+\left(\mathrm{PW}_{\mathrm{C}}+\right.\right.\right. \\
\left.\left.\left.\mathrm{d}_{\mathrm{PW}}\right)\right)^{3}-\mathrm{EDD}_{\mathrm{C}}{ }^{3}\right]-13.6
\end{gathered}
$$

by varying the variables $d_{S E P}$ and $d_{P W}$.

In the second case, we let the variable $d_{P w}$ be zero, and evaluated the function

$$
\begin{gathered}
\mathrm{LVM}=1.04 \times\left[\left(\left(\mathrm{EDD}_{\mathrm{C}}+\mathrm{d}_{\mathrm{EDD}}\right)+\left(\mathrm{SEP}_{\mathrm{C}}+\mathrm{d}_{\mathrm{SEP}}\right)+\right.\right. \\
\left.\left.\mathrm{PW}_{\mathrm{C}}\right)^{3}-\left(\mathrm{EDD}_{\mathrm{C}}+\mathrm{d}_{\mathrm{EDD}}\right)^{3}\right]-13.6
\end{gathered}
$$

by varying the variables $d_{\text {EDD }}$ and $d_{\text {SEP }}$.

In the third case, we let the variable $d_{\mathrm{SEP}}$ be zero, and evaluated the function

$$
\begin{aligned}
L V M= & 1.04 \times\left[\left(\left(E D_{C}+d_{E D D}\right)+\left(P W_{C}+d_{P W}\right)+\right.\right. \\
& \left.\left.S E P_{C}\right)^{3}-\left(E D D D_{C}+d_{E D D}\right)^{3}\right]-13 \cdot 6
\end{aligned}
$$

by varying the variables $d_{E D D}$ and $d_{P W}$.

The functions are shown in figs 1 and 2 .

For all our graphs, we used the relative scale-that is, we expressed each error quantity as a percentage of the corresponding value for the variable. 
Figure 1 Influence of measurement inaccuracies of the thickness of the interventricular septum (SEP) and of the posterior wall (PW) on the left ventricular mass (LVM) determined by $M$ mode echocardiography. An overestimation of both SEP and $P W$ of $5 \%$ leads to an LVM change of $8 \%$.

Figure 2 Influence of measurement inaccuracies of the end diastolic diameter of the left ventricle (EDD) and of the thickness of the interventricular septum (SEP) on the left ventricular mass (LVM) determined by $M$ mode echocardiography. An EDD inaccuracy of $3 \%$ combined with a SEP inaccuracy of $8 \%$ leads to a LVM change of $12 \%$. In this graph SEP can be replaced by the posterior wall thickness (PW) because both variables play equal parts in Devereux's formula.
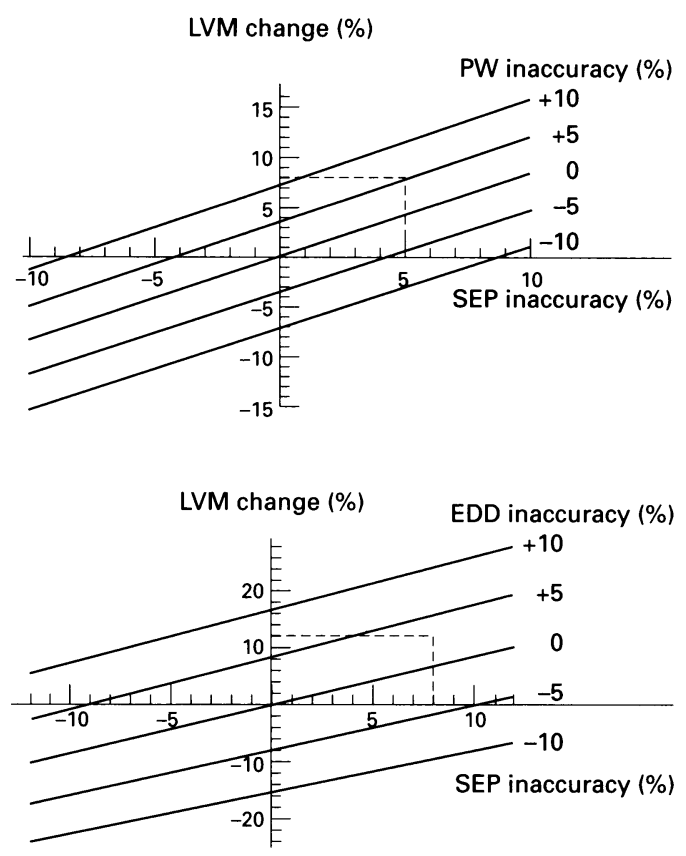

\section{Results}

Figure 1 shows the influence of SEP and PW measurement inaccuracies on LVM. An overestimation of both SEP and PW of $5 \%$ leads to a LVM change of $8 \%$.

Figure 2 shows the influence of EDD and either SEP or PW inaccuracy. An EDD inaccuracy of $3 \%$ combined with a SEP (or PW) inaccuracy of $8 \%$ leads to an LVM change of $12 \%$. The curves in figs 1 and 2 show that the measurement inaccuracies can compensate for one another, too- as would be the case if SEP were overestimated by $9 \%$ and PW underestimated by $10 \%$, simultaneously.

Though the curves in figs 1 and 2 seem to be straight lines, the functional dependence is not linear because of the cubic character of the Devereux's formula.

\section{Discussion}

Although magnetic resonance imaging has been shown to be a more reproducible tool for measuring LVM, at present echocardiography is the most commonly used method used to measure LVM. ${ }^{5}$ A "limited" echocardiogram is recommended as a cost effective technique that will assist in determining prognosis and evaluating the success or failure of antihypertensive treatment. ${ }^{7}$

In this study we showed how measurement inaccuracies of SEP, PW, and EDD influence
LVM. Measurement inaccuracies of EDD influence LVM more than errors of SEP or PW because EDD appears twice in Devereux's formula. Echocardiographic measurement inaccuracies are unavoidable especially in elderly and obese subjects, a clinical situation commonly encountered in hypertensive patients. Although known for a long time, ${ }^{4}$ even the use of cross sectionally guided $M$ mode echocardiography could not overcome this methodological problem: A recent study showed an intraobserver variability of $8.2 \%$ for SEP, $6.9 \%$ for PW and $2.3 \%$ for EDD when one investigator read 35 studies of hypertensive patients 1-2 weeks apart. ${ }^{6}$ The same authors found an interobserver variability between two observers of $9 \cdot 1 \%$ for SEP, $8 \cdot 7 \%$ for PW, and $3 \cdot 1 \%$ for EDD. ${ }^{6}$ As our graphs show, these inaccuracies in the measurement of SEP, PW, and EDD will result in "changes" of LVM in the range of $8 \%$ to $15 \%$. This is equivalent to changes observed during antihypertensive therapy. ${ }^{8}$

Because the calculation of LVM is already integrated into the software of the echocardiographic machine, clinicians are in danger of relying on this "measurement". We propose that those who use LVM determined by $M$ mode echocardiography should be aware of its susceptibility to measurement inaccuracy, especially in clinical decision making and in monitoring regression and progression of LVM in an individual patient.

We thank Dr Josef Finsterer for helpful suggestions.

1 Levy D, Garrison RJ, Savage DD, Kannel WB, Castelli WP. Prognostic implications of echocardiographically determined left ventricular mass in the Framingham heart study. N Engl f Med 1990;322:1561-6.

2 Casale PN, Devereux RB, Milner M, Zullo G, Harshfield GA, Pickering TG, et al. Value of echocardiographic measurement of left ventricular mass in predicting cardiovascular morbid events in hypertensive men. Ann diovascular morbid events
Intern Med 1986;105:173-8.

3 Devereux RB, Reichek N. Echocardiographic determination of left ventricular mass in man. Anatomic validation of the method. Circulation 1977;55:613-8.

4 Stefadouros MA, Canedo MI. Reproducibility of echocardiographic estimates of left ventricular dimensions. $\mathrm{Br}$ Heart $\mathcal{F}$ 1977;39:390-8.

5 Germain P, Roul G, Kastler B, Mossard JM, Bareiss P, Sacrez A. Inter-study variability in left ventricular mass measurement. Comparison between $M$-mode echography and MRI. Eur Heart f 1992;13:1011-9.

6 Gottdiener JS, Livengood SV, Meyer PS, Chase GA. Should echocardiography be performed to assess effects of antihypertensive therapy? Test-retest reliability of echocardiography for measurement of left ventricular mass and function. $\mathcal{F}$ Am Coll Cardiol 1995;25:424-30.

7 Black HR, Weltin G, Jaffe CC. The limited echocardiogram: a modification of standard echocardiography for the use in the routine evaluation of patients with systemic the use in the routine evaluation of patients with
hypertension. Am $\mathcal{F}$ Cardiol 1991;67:1027-30.

8 Dahlöf B, Pennert K, Hansson L. Reversal of left ventricular hypertrophy in hypertensive patients. A metaanalysis of 109 treatment studies. Am $\mathcal{H}$ Hypertens 1992;5:95-110. 